\title{
ANALISIS PEMILIHAN BEASISWA KURANG MAMPU PADA SEKOLAH DASAR KATOLIK HATI KUDUS SAMARINDA
}

\author{
Anton Topadang'), Irwansyah' ${ }^{2}$, Safruddin $^{3)}$ \\ ${ }^{1)}$ Program Studi Teknik Informatika Multimedia, Politeknik Negeri Samarinda \\ ${ }^{2,3)}$ Program Studi Teknologi Rekayasa Komputer, Politeknik Negeri Samarinda \\ E-mail: antontopadang@polnes.ac.id ${ }^{1}$, irwan_it_polnes@yahoo.co.id² ${ }^{2}$, udinadil99@gmail.com
}

\begin{abstract}
Abstrak - Salah satu perhatian pemerintah atau pihak swasta adalah memberikan beasiswa kepada siswa dalam berbagai jenis beasiswa. Program beasiswa diadakan untuk meringankan beban siswa dalam menempuh masa belajar siswa. Pemberian beasiswa haruslah dilakukan secara selektif agar tepat sasaran. Setiap jenis beasiswa memiliki kriteria dan bobot penilaian yang berbeda-beda, salah satunya beasiswa yang diberikan untuk siswa yang berasal dari keluarga kurang mampu. Walaupun pihak pemerintah sudah membantu dengan menerbitkan Kartu Indonesia Pintar (KIP) untuk keluarga kurang mampu. Tetapi tidak semua siswa kurang mampu memiliki KIP, apalagi untuk siswa yang bersekolah di sekolah swasta. Dalam menentukan dan menetapkan penerima beasiswa pihak sekolah masih secara manual dengan menggunakan microsoft excel dalam perhitungan dan tentu memiiki kekurangan dalam keakuratan hasil sehingga hasilnya tidak tepat sasaran. Oleh karena itu perlu digunakan sebuah metode pengambilan keputusan yang bisa membantu dalam pemilihan siswa penerima beasiswa kurang mampu. Metode yang digunakan dalam penelitian ini adalah Simple Additive Weighting (SAW). Metode Simple Additive Weighting (SAW) adalah salah satu metode yang bisa digunakan sebagai alternatif untuk membantu pengambilan keputusan penerimaan beasiswa. Pada penerapan metode SAW untuk menentukan beasiswa kurangmampu, digunakan empat kriteria yaitu adalah 1) Penghasilan Orang Tua(C1), 2) Tanggungan Orang Tua(C2), 3) Saudara Kandung(C3), dan 4) Pengeluaran Orang Tua(C4). Hasil analisis algoritma SAW diperoleh rangking 1 = Alternatif 9(A9) dengan nilai=0,892, ranking $2=$ Alternatif 10(A10) dengan nilai=0,866, dan ranking $3=$ Alternatif 5(A5) dengan nilai $=0,826$. Berdasarkan ranking tersebut pihak kepala sekolah dapat menjadikan acuan dalam menetapkan penerima beasiswa kurang mampu pada Sekolah Dasar Katolik Hati Kudus Samarinda.
\end{abstract}

Kata kunci: Beasiswa, Simple Additive Weighting.

\section{PENDAhuluan}

Salah satu perhatian pemerintah atau pihak swasta kepada siswa adalah memberikan beasiswa dalam berbagai jenis. Pemberian beasiswa merupakan program kerja rutin yang ada di setiap sekolah. Program beasiswa diadakan untuk meringankan beban siswa dalam menempuh masa belajar khususnya dalam masalah biaya. Pemberian beasiswa kepada siswa ini haruslah dilakukan secara selektif sesuai dengan jenis beasiswa yang diadakan.

Setiap jenis beasiswa memiliki kriteria atau faktor bobot penilaian yang berbeda-beda, salah satunya beasiswa yang diberikan untuk siswa yang berasal dari keluarga kurang mampu yang haruslah sesuai kemampuan ekonomi yang sebenarnya sehingga tidak kesulitan dalam pembiayaan sekolah.

Walaupun pihak pemerintah sudah membantu dengan menerbitkan Kartu Indonesia Pintar (KIP) untuk keluarga kurang mampu. Tetapi tidak semua siswa kurang mampu memiliki KIP, sehingga perlu diusulkan beasiswa dengan pertimbangan ekonomi keluarga, seperti Jumlah Penghasilan Orang Tua, Jumlah Tanggungan Orang Tua, Jumlah saudara, dan Jumlah Pengeluaran Orang Tua Per Bulan.

Perlu digunakan sebuah program dengan metode pengambilan keputusan yang bisa membantu dalam pemilihan siswa penerima beasiswa kurang mampu. Sebelumnya masih dilakukan secara manual dengan menggunakan sorting pada microsof excel yang masih memiliki kekurangan dalam ketepatan hasil, sehingga beasiswa yang diberikan kurang tepat sasaran.

Metode Simple Additive Weighting (SAW) adalah salah satu metode yang bisa digunakan sebagai alternatif untuk membantu pengambilan keputusan penerimaan beasiswa. Pada metode SAW menggunakan penjumlahan berbobot pada setiap kriteria sehingga cocok dengan kasus pemilihan calon siswa penerima 
beasiswa yang menggunakan 4 kriteria. Pada setiap kriteria diberi bobot atau tingkat kepentingan sesuai dengan kondisi di sekolah, supaya hasil perhitungan metode SAW lebih akurat.

\section{PENGERTIAN BEASISWA}

Beasiswa adalah tunjangan yang diberikan kepada pelajar atau mahasiswa sebagai bantuan biaya belajar(KBBI). Menurut Murniasih bahwa beasiswa adalah bentuk penghargaan yang diberikan kepada individu agar dapat melanjutkan pendidikannya ke jenjang yang lebih tinggi[1]. Sedangkan menurut $\mathrm{P}$ Dauni dkk, Beasiswa adalah pemberian berupa bantuan keuangan dalam pendidikan yang diberikan kepada pelajar yang bertujuan untuk keberlangsungan pendidikannya[2]. Dari pengertian beasiswa tersebut, sudah jelas bahwasanya beasiswa merupakan bantuan biaya sehingga seorang pelajar bisa mengikuti kegiatan belajar dengan biaya yang lebih ringan. Beasiswa dapat dibedakan menjadi beasiswa penuh dan parsial. Sumber beasiswa dapat berasal dari pemerintah atau dari pihak swasta.

Agar pemberian beasiswa tepat sasaran maka penyeleksian penerimaan beasiwa harus menggunakan parameter atau kriteria yang tepat. Saat ini keputusan yang harus dikeluarkan terhadap penerima beasiswa oleh lembaga pendidikan masih dinilai kurang tepat, karena masih bersifat subjektif, yang didasarkan pada faktor kekeluargaan, hubungan kedekatan dan lainnya, bukan dikarenakan kurang mampu, prestasi yang pernah dicapai ataupun keaktifan dalam berorganisasi di lembaga pendidikan, sehingga ketercapaian dari manfaat pemberian beasiswa kurang tepat.

Oleh karena itu diperlukan suatu sistem yang memberikan bantuan dukungan terhadap keputusan yang dihasilkan oleh pihak lembaga pendidikan. Sistem ini dikenal dengan nama Sistem Pendukung Keputusan(SPK) [3],[4],[5]. Hasil dukungan keputusan yang diberikan sesuai dengan penyeleksian terhadap kriteria yang ditentukan, misalnya ranking rendahnya pendapatan orang tua jumlah tanggungan orang tua, jumlah bersudara, dan jumlah pengeluaran orang tua per bulan. Penerapan sistem pendukung keputusan dalam pemberian dukungan terhadap keputusan pimpinan lembaga bukan merupakan hal yang baru disaat ini. Telah banyak penelitian yang dilakukan oleh kalangan peneliti, terkait dengan suatu keputusan yang akan di ambil oleh pimpinan.

Pada penelitian ini, penulis menggunakan metode Simple Additive Weighting(SAW) dalam mendapatkan keputusan tentang calon penerima bantuan siswa kurang mampuatau miskin. Keunggulan dari metode Simple Additive Weighting dibandingan dengan metode sistem keputusan yang lain terletak pada kemampuannya dalam melakukan penelitian secara lebih tepat karena didasarkan pada nilai kriteria dan bobot tingkat kepentingan yang dibutuhkan.

Dalam metode SAW juga dapat menyeleksi alternatif terbaik dari sejumlah alternatif yang ada kemudian dilakukannya proses perangkingan yang jumlah nilai bobit dari semua kriteria dijumlahkan setelah menentukan nilai bobot dari setiap kriteria. Pada intinya bahwa metode SAW ini menentukan nilai bobot pada setiap kriteria untuk menentukan alternatif siswa kurang mampu yang berhak menerima beasiswa

\section{PENELITIAN YANG RELEVAN}

Hasanah R, dalam penelitiannya dengan judul "Sistem Pendukung Keputusan Untuk Menentukan PenerimaBeasiswa Dengan Metode Simple Additive Weighting (Saw) (Studi Kasus Pada Mts Al-Maidah Kotasan)[6], penelitin tersebut menghasilkan ranking nilai penerima beasiswa yang selanjutnya menjai acuan bagi pihak yang berwewenang untuk menentukan penerima beasiswa.

Penelitian dari Nalsa Cintya Resti , 2017, dengan judul : Penerapan Metode Simple Additive Weighting (SAW) pada Sistem Pendukung Keputusan Pemilihan Lokasi untuk Cabang Baru Toko Pakan UD. Indo Multi Fish. Dari penelitian tersebut bahwa alternatif yaitu daerah Ngunut dapat dijadikan sebagai rekomendasi daerah untuk cabang baru toko UD Indo Multi Fish. Hal ini dikarenakan daerah Ngunut memiliki ranking tertinggi dalam perhitungan dibandingkan daerah yang lain[7].

Aning Setiya Rini dan Dewi Soyusiawaty, dalam Sistem Pendukung Keputusan Seleksi Penerimaan Beras Untuk Keluarga Miskin Dengan Metode Simple Additive Weighting, dengan hasil penelitian berupa Aplikasi Sistem Pendukung Keputusan Seleksi Penerimaan Raskin menggunakan metode $S A W$ ini telah diuji dan dapat berguna bagi kelurahan warungboto yang ingin menyeleksi warganya. Informasi dapat diperoleh dengan mudah, sehingga pembagian raskin tepat sasaran[8].

Penelitian Reza Fauzan, dkk dengan judul: Sistem Pendukung Keputusan Penerimaan Beasiswa Bidik Misi di POLIBAN Dengan Metode SAW Berbasis Web, dengan menghasilkan penelitian berupa Sistem Pendukung Keputusan enerimaan Beasiswa Bidik Misi ini dapat dengan baik melakukan perangkingan[9]. 
Penelitian Reza Fauzan, dkk, 2017 dengan judul : "Sistem Pendukung Keputusan Penerimaan Beasiswa Bidik Misi di POLIBAN Dengan Metode SAW Berbasis Web" dengan hasil penelitian Sistem Pendukung Keputusan Penerimaan Beasiswa Bidik Misi ini dapat dengan baik melakukan perangkingan. [10].

\section{METODOLOGI PENELITIAN}

Metodologi penelitian yang dilakukan pada penelitian ini seperti pada gambar 1 berikut:

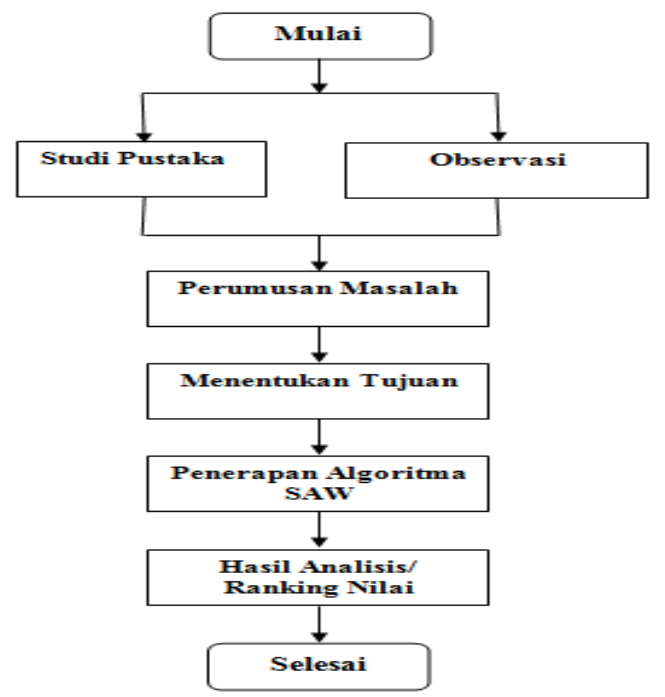

Gambar 1. Metodologi penelitian

\section{a) Studi Pustaka}

Studi pustaka adalah proses mencari literatur yang berisi teori-teori yang berkaitan dengan masalah yang akan dibahas.Dalam penyusunan laporan ini penulis mencari informasi melalui buku referensi dan jurnaljurnal penelitian terdahulu. Skala pengukuran yang dipakai dalam kuesioner ini adalah skala guttman, yang menampilkan beberapa pernyataan yang dibuat dalam bentuk checklist. Jawaban dapat dibuat skor tertinggi satu dan terendah nol.

\section{b) Observasi}

Observasi adalah pengamatan langsung terhadap kegiatan yang diteliti. Dalam penyusunan penelitian ini penulis melakukan pengamatan secara langsung dengan Sekolah Dasar Katolik Hati Kudus untuk mendapatkan data yang dibutuhkan terkait penelitian.

\section{c) Rumusan masalah}

Rumusan masalah dalam penelitian ini adalah bagaimana menganalisis data-data kriteria siswa kurang mampu menggunakan algortima pada metode Simple Additive Weighting (SAW).

\section{d) Menentukan Tujuan}

Tujuan yang hendakdicapai pada penelitian ini adalah untuk mendapatkan ranking nilai siswa yang dapat direkomendasikan sebagai penerima beasiswa kurang mampu.

\section{e) Penerapan Algoritma SAW}

Langkah selanjutnya adalah inti dari penelitian ini yaitu penerapan algoritma dari metode Simple Additive Weighting(SAW), dimana langkah-langkahnya sepertipada point tiga di bawah. Dan hasil akhir dari penerpan algortima SAW, dieroleh ranking nilaisiswa kurang mampu.

\section{SIMPLE ADDITIVE WEIGHTING}

Metode Simple Additive Weighting (SAW) sering juga dikenal istilah metode penjumlahan terbobot. Konsep dasar metode SAW adalah mencari penjumlahan terbobot dari rating kinerja pada setiap alternatif pada semua atribut , Fishburn,1967[5]. Konsep dasar metode SAW adalah mencari penjumlahan terbobot dari rating kinerja pada setiap alternatif pada semua kriteria[3]. Metode SAW mengenal adanya 2 (dua) atribut yaitu kriteria keuntungan (benefit) dan kriteria biaya (cost). Perbedaan mendasar dari kedua kriteria ini adalah dalam pemilihan kriteria ketika mengambil keputusan. Adapun langkah penyelesaian atau algoritma SAW adalah sebagai berikut:

a. Menentukan alternatif, yaitu Ai.

b. Menentukan kriteria yang akan dijadikan acuan dalam pengambilan keputusan, yaitu $\mathrm{Cj}$.

c. Memberikan nilai rating kecocokan setiap alternatif pada setiap kriteria.

d. Menentukan bobot preferensi atau tingkat kepentingan (W) setiap kriteria.

$\mathrm{W}=[\mathrm{W} 1, \mathrm{~W} 2, \mathrm{~W} 3, \ldots \mathrm{Wj}]$

(1)

e. Membuat tabel rating kecocokan dari setiap alternatif pada setiap kriteria.

f. Membuat matrik keputusan $X$ yang dibentuk dari tabel rating kecocokan dari setiap alternatif padasetiap kriteria. Nilai X setiap alternatif (Ai) pada setiap kriteria (Cj) yang sudah ditentukan, dimana, $i=1,2, \ldots m$ dan $j=1,2, \ldots n$.

g. Melakukan normalisasi matrik keputusan X dengan cara menghitung nilai rating kinerja ternomalisasi (rij) dari alternatif Ai pada kriteria $\mathrm{Cj}$.

\section{Keterangan :}

1. Dikatakan kriteria keuntungan apabila nilai Xij memberikan keuntungan bagi pengambil keputusan, sebaliknya kriteria biaya apabila Xij menimbulkan biaya bagi pengambil keputusan.

2. Apabila berupa kriteria keuntungan maka nilai Xij dibagi dengan nilai Maxi(Xij) dari setiap kolom, sedangkan untuk kriteria biaya, nilai 
Mini(Xij) dari setiap kolom dibagi dengan nilai Xij.

h. Hasil dari nilai rating kinerja ternomalisasi (rij) membentuk matrik ternormalisasi (R)

i. Hasil akhir nilai preferensi (Vi) diperoleh dari penjumlahan dari perkalian elemen baris matrik ternormalisasi (R) dengan bobot preferensi (W) yang bersesuaian eleman kolom matrik (W). Hasil perhitungan nilai $\mathrm{Vi}$ yang lebih besar mengindikasikan bahwa alternatif $\mathrm{Ai}$ merupakan alternatif terbaik. Metode SAW membutuhkan proses normalisasi matriks keputusan $(\mathrm{X})$ ke suatu skala yang dapat diperbandingkan dengan semua rating alternative yang ada[3].

Berikut rumus SAW :

$$
=\left\{\begin{array}{l}
\frac{x_{i j}}{\max _{i} x_{i j}} j i k a j \text { adalah atribut } k \\
\frac{\min _{i} x_{i j}}{x_{i j}} j i k a j \text { adalah atribut } b
\end{array}\right.
$$

Sumber: (Nofriansyah, 2014)

\section{Keterangan :}

rij = nilai rating kinerja ternormalisasi

xij $=$ nilai atribut yang dimiliki dari setiap criteria

Max xij = nilai terbesar dari setiap criteria Min $x i j=$ nilai terkecil dari setiap criteria benefit $=$ jika nilai terbesar adalah terbaik cost $=$ jika nilai terkecil adalah terbaik dimana rij adalah rating kinerja ternormalisasi dari alternative ai pada atribut $\mathrm{Cj} ; \mathrm{i}=1,2, \ldots, \mathrm{m}$ dan $\mathrm{j}=1,2, \ldots, n$. Nilai presensi untuk setiap alternative(Vi) diberikan sebagai:

$$
V_{i} \sum_{j=1}^{n} W_{j} r_{i j}
$$

\section{Keterangan :}

$\mathrm{Vi}=$ rangking untuk setiap alternative

$\mathrm{Wj}=$ nilai bobot dari setiap criteria

rij = nilai rating kinerja ternormalisasi

\section{HASIL DAN PEMBAHASAN}

\subsection{Menentukan Kriteria dan Bobot}

Berikut merupakan kriteria yang dibutuhkan untuk pengambilan keputusan berdasarkan persyaratan dari metode Simple Additive Weighting ( $S A W$ ) yaitu:

a. Jumlah Penghasilan Orang Tua (C1) b. Jumlah Tanggungan Orang Tua(C2)

c. Jumlah saudara(C3)

d. Jumlah Pengeluaran Orang Tua Per Bulan(C4)

Adapun Nilai Bobot dari masing-masing kriteria tersebut adalah sebagai berikut:

\subsubsection{Bobot dan Nilai Kriteria}

Tabel 1. Bobot Beasiswa Kurang Mampu

\begin{tabular}{ccccc}
\hline Kode & Kriteria & Bobot & Nilai & Tipe \\
\hline C1 & $\begin{array}{c}\text { Penghasilan } \\
\text { Orang Tua }\end{array}$ & Tinggi & 0.4 & Cost \\
C2 & $\begin{array}{c}\text { Tanggungan } \\
\text { Orang Tua }\end{array}$ & Cukup & 0.2 & Benefit \\
C3 & $\begin{array}{c}\text { Saudara } \\
\text { Kandung }\end{array}$ & Sedang & 0.2 & Benefit \\
C4 & $\begin{array}{c}\text { Pengeluaran } \\
\text { Orang Tua }\end{array}$ & Tinggi & 0.2 & Benefit \\
\hline
\end{tabular}

Dari Tabel 1 diperoleh nilai bobot (W) dengan data :

$$
\mathrm{W}=[0.4,0.2,0.2,
$$

\subsubsection{Kriteria Jumlah Penghasilan Orang Tua(C1)}

Tabel 2. Penghasilan Orang Tua

\begin{tabular}{c|l|c}
\hline Penghasilan Orang Tua $($ C1) & Variabel & Bobot \\
\hline $\mathrm{C} 1<\mathrm{Rp} 1.000 .000$ & Rendah $(\mathrm{R})$ & 0.2 \\
\hline $\mathrm{Rp} 1.000 .000<\mathrm{C} 1<\mathrm{Rp} 2.000 .000$ & Sedang $(\mathrm{S})$ & 0.4 \\
\hline $\mathrm{Rp} 2.000 .000<\mathrm{C} 1<\mathrm{Rp} 3.000 .000$ & Cukup $(\mathrm{C})$ & 0.6 \\
\hline $\mathrm{Rp} 3.000 .000<\mathrm{C} 1<\mathrm{Rp} 4.000 .000$ & Tinggi $(\mathrm{T})$ & 0.8 \\
\hline $\mathrm{C} 1<\mathrm{Rp} 4.000 .000$ & $\begin{array}{c}\text { Sangat Tinggi } \\
\text { (ST) }\end{array}$ & 1 \\
\hline
\end{tabular}

\subsubsection{Kriteria Jumlah Tanggungan Orang Tua(C2)}

Tabel 3. Jumlah Tanggungan Orang Tua

\begin{tabular}{ccc}
\hline $\begin{array}{c}\text { Jumlah Tanggungan } \\
\text { Orang Tua (C2) }\end{array}$ & Variabel & Bobot \\
\hline 1 orang & Rendah (R) & 0.2 \\
2 orang & Sedang (S) & 0.4 \\
3 orang & Cukup (C) & 0.6 \\
4 orang & Tinggi (T) & 0.8 \\
C2 $>$ 4orang & Sangat Tinggi (ST) & 1 \\
\hline
\end{tabular}

\subsubsection{Kriteria Jumlah Saudara}

Kandung(C3)

Tabel 4. Jumlah Saudara Kandung

\begin{tabular}{ccc}
\hline $\begin{array}{c}\text { Jumlah Saudara } \\
\text { Kandung }(\mathbf{C 3})\end{array}$ & Variabel & Bobot \\
\hline 1orang & Rendah (R) & $\mathbf{0 . 2}$ \\
2orang & Sedang (S) & $\mathbf{0 . 4}$ \\
3orang & Cukup (C) & $\mathbf{0 . 6}$ \\
\hline
\end{tabular}




\begin{tabular}{ccc}
\hline 4orang & Tinggi (T) & 0.8 \\
C3 > 4orang & Sangat Tinggi & 1 \\
& (ST) & \\
\hline
\end{tabular}

\subsubsection{Kriteria Jumlah Pengeluaran Orang} Tua Per Bulan(C4)

Tabel 5. Pengeluaran Orang Tua Per Bulan

\begin{tabular}{|c|c|c|}
\hline $\begin{array}{l}\text { Pengeluaran Orang Tua } \\
\text { Perbulan (C4) }\end{array}$ & Variabel & Bobot \\
\hline C5 $<$ Rp 1.000 .000 & Rendah (SR) & 0.2 \\
\hline $\operatorname{Rp} 1.000 .000<\mathrm{C} 4<\operatorname{Rp} 2.000 .000$ & Sedang (R) & 0.4 \\
\hline $\operatorname{Rp} 2.000 .000<\mathrm{C} 4<\operatorname{Rp} 3.000 .000$ & Cukup (S) & 0.6 \\
\hline $\operatorname{Rp} 3.000 .000<\mathrm{C} 4<\operatorname{Rp} 4.000 .000$ & Tinggi (T) & 0.8 \\
\hline$<\mathrm{C} 4<\mathrm{Rp} 4.000 .000$ & Sangat Tinggi (ST) & 1 \\
\hline
\end{tabular}

\subsection{Data Sampel Siswa}

Simulasi metode perhitungan yang penulis lakukan menggunakan data dummy siswa sebagai alternatif.

Tabel 6. Data sampel siswa kurang mampu

\begin{tabular}{|c|c|c|c|c|c|}
\hline \multirow[b]{2}{*}{ No } & \multirow[b]{2}{*}{$\begin{array}{c}\text { Alter- } \\
\text { natif }\end{array}$} & \multicolumn{4}{|c|}{ Kriteria } \\
\hline & & $\begin{array}{l}\text { Penghasilan Orang } \\
\text { Tua(Rp.)(C1) }\end{array}$ & $\begin{array}{c}\text { Tanggungan } \\
\text { Orang Tua(C2) }\end{array}$ & $\begin{array}{c}\text { Jumlah } \\
\text { Saudara } \\
\text { Kandung(C3) }\end{array}$ & $\begin{array}{l}\text { Jumlah Pengeluaran } \\
\text { Per Bulan(Rp.)(C4) }\end{array}$ \\
\hline 1 & A1 & 750.000 & 4 & 3 & 1.500 .000 \\
\hline 2 & A2 & 1.250 .000 & 5 & 4 & 1.750 .000 \\
\hline 3 & A3 & 2.000 .000 & 7 & 6 & 2.500 .000 \\
\hline 4 & A4 & 1.500 .000 & 3 & 5 & 1.750 .000 \\
\hline 5 & A5 & 800.000 & 6 & 5 & 1.350 .000 \\
\hline 6 & A6 & 1.100 .000 & 4 & 4 & 1.500 .000 \\
\hline 7 & A7 & 1.700 .000 & 3 & 5 & 2.100 .000 \\
\hline 8 & A8 & 1.250 .000 & 7 & 6 & 1.300 .000 \\
\hline 9 & A9 & 750.000 & 4 & 5 & 1.500 .000 \\
\hline 10 & A10 & 900.000 & 5 & 6 & 1.750 .000 \\
\hline
\end{tabular}

\subsection{Menentukan Rating Kecocokan Alternatif}

Tabel 7. Rating Kecocokan Alternatif

\begin{tabular}{ccccc}
\hline \multirow{2}{*}{ Alternatif } & \multicolumn{4}{c}{ Kriteria } \\
\cline { 2 - 5 } & C1 & C2 & C3 & C4 \\
\hline A1 & 0.2 & 0.4 & 0.4 & 0.8 \\
A2 & 0.4 & 0.2 & 0.6 & 0.8 \\
A3 & 0.6 & 0.2 & 1 & 0.6 \\
A4 & 0.4 & 0.6 & 0.8 & 0.8 \\
A5 & 0.2 & 0.2 & 0.8 & 0.8 \\
A6 & 0.4 & 0.4 & 0.4 & 0.8 \\
A7 & 0.4 & 0.6 & 0.8 & 0.6 \\
A8 & 0.4 & 0.2 & 1 & 0.8 \\
A9 & 0.2 & 0.4 & 0.8 & 0.8 \\
A10 & 0.2 & 0.2 & 1 & 0.8 \\
\hline
\end{tabular}

Berdasarkan tabel rating kecocokan di atas, selanjutnya dibuat dalam matriks keputusan X sebagai berikut :

$$
X=\left|\begin{array}{cccc}
0.2 & 0.4 & 0.4 & 0.8 \\
0.4 & 0.2 & 0.6 & 0.8 \\
0.6 & 0.2 & 1 & 0.6 \\
0.4 & 0.6 & 0.8 & 0.8 \\
0.2 & 0.2 & 0.8 & 0.8 \\
0.4 & 0.4 & 0.4 & 0.8 \\
0.4 & 0.6 & 0.8 & 0.6 \\
0.4 & 0.2 & 1 & 0.8 \\
0.2 & 0.4 & 0.8 & 0.8 \\
0.2 & 0.2 & 1 & 10.8
\end{array}\right|
$$

\subsection{Normalisasi matrik keputusan (X)}

Selanjutnya melakukan normalisasi matrik keputusan $(\mathrm{X})$ dengan cara menghitung nilai rating kinerja ternormalisasi (rij) dari setiap alternatif pada setiap kriteria. Setelah dijadikan matriks kemudian nilai matriks di atas dinormalisasikan dengan rumus .....2).

Dengan menggunakan rumus normalisasi tersebut, maka dapat dihitung r11...r104 sebagai berikut

$$
\begin{aligned}
& r 11=\frac{\min (0.2 ; 0.4 ; 0.6 ; 0.4 ; 0.2 ; 0.4 ; 0.4 ; 0.4 ; 0.2 ; 0.2)}{0.2}=\frac{0.2}{0.2}=1 \\
& r 21=\frac{\min (0.2 ; 0.4 ; 0.6 ; 0.4 ; 0.2 ; 0.4 ; 0.4 ; 0.4 ; 0.2 ; 0.2)}{0.4}=\frac{0.2}{0.4}=0.5 \\
& r 31=\frac{\min (0.2 ; 0.4 ; 0.6 ; 0.4 ; 0.2 ; 0.4 ; 0.4 ; 0.4 ; 0.2 ; 0.2)}{0.6}=\frac{0.2}{0.6}=0.33 \\
& r 41=\frac{\min (0.2 ; 0.4 ; 0.6 ; 0.4 ; 0.2 ; 0.4 ; 0.4 ; 0.4 ; 0.2 ; 0.2)}{0.4}=\frac{0.2}{0.4}=0.5 \\
& r 51=\frac{\min (0.2 ; 0.4 ; 0.6 ; 0.4 ; 0.2 ; 0.4 ; 0.4 ; 0.4 ; 0.2 ; 0.2)}{0.2}=\frac{0.2}{0.2}=1 \\
& r 61=\frac{\min (0.2 ; 0.4 ; 0.6 ; 0.4 ; 0.2 ; 0.4 ; 0.4 ; 0.4 ; 0.2 ; 0.2)}{0.4}=\frac{0.2}{0.4}=0.5 \\
& r 71=\frac{\min (0.2 ; 0.4 ; 0.6 ; 0.4 ; 0.2 ; 0.4 ; 0.4 ; 0.4 ; 0.2 ; 0.2)}{0.4}=\frac{0.2}{0.4}=0.5 \\
& r 81=\frac{\min (0.2 ; 0.4 ; 0.6 ; 0.4 ; 0.2 ; 0.4 ; 0.4 ; 0.4 ; 0.2 ; 0.2)}{0.4}=\frac{0.2}{0.4}=0.5 \\
& r 91=\frac{\min (0.2 ; 0.4 ; 0.6 ; 0.4 ; 0.2 ; 0.4 ; 0.4 ; 0.4 ; 0.2 ; 0.2)}{0.2}=\frac{0.2}{0.2}=1 \\
& r 101=\frac{\min (0.2 ; 0.4 ; 0.6 ; 0.4 ; 0.2 ; 0.4 ; 0.4 ; 0.4 ; 0.2 ; 0.2)}{0.2}=\frac{0.2}{0.2}=1
\end{aligned}
$$




$$
\begin{aligned}
& r 14=\frac{0.8}{\max (0.8 ; 0.8 ; 0.6 ; 0.8 ; 0.8 ; 0.8 ; 0.6 ; 0.8 ; 0.8 ; 0.8)}=\frac{0.8}{0.8}=1 \\
& r 24=\frac{0.8}{\max (0.8 ; 0.8 ; 0.6 ; 0.8 ; 0.8 ; 0.8 ; 0.6 ; 0.8 ; 0.8 ; 0.8)}=\frac{0.8}{0.8}=1 \\
& r 34=\frac{0.6}{\max (0.8 ; 0.8 ; 0.6 ; 0.8 ; 0.8 ; 0.8 ; 0.6 ; 0.8 ; 0.8 ; 0.8)}=\frac{0.6}{0.8}=0.75 \\
& r 44=\frac{0.8}{\max (0.8 ; 0.8 ; 0.6 ; 0.8 ; 0.8 ; 0.8 ; 0.6 ; 0.8 ; 0.8 ; 0.8)}=\frac{0.8}{0.8}=1 \\
& r 54=\frac{0.8}{\max (0.8 ; 0.8 ; 0.6 ; 0.8 ; 0.8 ; 0.8 ; 0.6 ; 0.8 ; 0.8 ; 0.8)}=\frac{0.8}{0.8}=1 \\
& r 64=\frac{0.8}{\max (0.8 ; 0.8 ; 0.6 ; 0.8 ; 0.8 ; 0.8 ; 0.6 ; 0.8 ; 0.8 ; 0.8)}=\frac{0.8}{0.8}=1 \\
& r 74=\frac{0.6}{\max (0.8 ; 0.8 ; 0.6 ; 0.8 ; 0.8 ; 0.8 ; 0.6 ; 0.8 ; 0.8 ; 0.8)}=\frac{0.6}{0.8}=0.75 \\
& r 84=\frac{0.8}{\max (0.8 ; 0.8 ; 0.6 ; 0.8 ; 0.8 ; 0.8 ; 0.6 ; 0.8 ; 0.8 ; 0.8)}=\frac{0.8}{0.8}=1 \\
& r 94=\frac{0.8}{\max (0.8 ; 0.8 ; 0.6 ; 0.8 ; 0.8 ; 0.8 ; 0.6 ; 0.8 ; 0.8 ; 0.8)}=\frac{0.8}{0.8}=1 \\
& r 104=\frac{0.8}{\max (0.8 ; 0.8 ; 0.6 ; 0.8 ; 0.8 ; 0.8 ; 0.6 ; 0.8 ; 0.8 ; 0.8)}=\frac{0.8}{0.8}=1
\end{aligned}
$$

Dengan menggunakan rumus normalisasi tersebut, maka diperoleh hasil perhitungan matriks ternormalisasi R berikut:

$$
R=\left|\begin{array}{cccc}
1 & 0.66 & 0.4 & 1 \\
0.5 & 0.33 & 0.66 & 1 \\
0.33 & 0.33 & 1 & 0.75 \\
0.5 & 1 & 0.8 & 1 \\
1 & 0.33 & 0.8 & 1 \\
0.5 & 0.66 & 0.4 & 1 \\
0.5 & 1 & 0.8 & 0.75 \\
0.5 & 0.33 & 1 & 1 \\
1 & 0.66 & 0.8 & 1 \\
1 & 0.33 & 1 & 1
\end{array}\right|
$$

Selanjutnya dilakukan perhitungan untuk mendapatkan ranking yaitu dengan menentukan terlebih dahulu nilai Vi dengan Rumus $\cdots \cdots 3$ ).

$$
\begin{aligned}
& \mathrm{V} 1=\left(0.4^{*} 1\right)+\left(0.2^{*} 0.66\right)+\left(0.2^{*} 0.4\right)+\left(0.2^{*} 1\right)=0.812 \\
& \mathrm{~V} 2=\left(0.4^{*} 0.5\right)+\left(0.2^{*} 0.33\right)+\left(0.2^{*} 0.66\right)+\left(0.2^{*} 1\right)=0.548 \\
& \mathrm{~V} 3=\left(0.4^{*} 0.33\right)+\left(0.2^{*} 0.33\right)+\left(0.2^{*} 1\right)+\left(0.2^{*} 0.75\right)=0.548 \\
& \mathrm{~V} 4=\left(0.4^{*} 0.5\right)+\left(0.2^{*} 1\right)+\left(0.2^{*} 0.8\right)+\left(0.2^{*} 1\right)=0.76 \\
& \mathrm{~V} 5=\left(0.4^{*} 1\right)+\left(0.2^{*} 0.33\right)+\left(0.2^{*} 0.8\right)+\left(0.2^{*} 1\right)=0.826 \\
& \mathrm{~V} 6=\left(0.4^{*} 0.5\right)+\left(0.2^{*} 0.66\right)+\left(0.2^{*} 0.4\right)+\left(0.2^{*} 1\right)=0.612 \\
& \mathrm{~V} 7=\left(0.4^{*} 0.5\right)+\left(0.2^{*} 1\right)+\left(0.2^{*} 0.8\right)+\left(0.2^{*} 0.75\right)=0.71 \\
& \text { V8 }=\left(0.4^{*} 0.5\right)+\left(0.2^{*} 0.33\right)+\left(0.2^{*} 1\right)+\left(0.2^{*} 1\right)=0.66 \\
& \text { V9 }=\left(0.4^{*} 1\right)+\left(0.2^{*} 0.66\right)+\left(0.2^{*} 0.8\right)+\left(0.2^{*} 1\right)=0.892 \\
& \text { V10 }=\left(0.4^{*} 1\right)+\left(0.2^{*} 0.33\right)+\left(0.2^{*} 1\right)+\left(0.2^{*} 1\right)=0.866
\end{aligned}
$$

Dari perhitungan Vi untuk semua calon penerima beasiswa kurang mampu maka diperoleh ranking seperti pada Tabel 8 berikut:
Tabel 8. Ranking Alternatif

\begin{tabular}{ccc}
\hline Ranking & Alternatif & Nilai \\
\hline $\mathbf{1}$ & A9 & $\mathbf{0 , 8 9 2}$ \\
$\mathbf{2}$ & A10 & $\mathbf{0 , 8 6 6}$ \\
$\mathbf{3}$ & A5 & $\mathbf{0 , 8 2 6}$ \\
$\mathbf{4}$ & A1 & $\mathbf{0 , 8 1 2}$ \\
$\mathbf{5}$ & A4 & $\mathbf{0 , 7 6 0}$ \\
$\mathbf{6}$ & A7 & $\mathbf{0 , 7 1 0}$ \\
7 & A8 & $\mathbf{0 , 6 6 0}$ \\
8 & A6 & $\mathbf{0 , 6 1 2}$ \\
9 & A2 & $\mathbf{0 , 5 4 8}$ \\
10 & A3 & $\mathbf{0 , 5 4 8}$ \\
\hline
\end{tabular}

Hasil akhir perhitungan dengan menerapkan metode Simple Additive Weighting (SAW), dapat diketahui alternatif dengan nilai tertinggi sampai terendah seperti pada tabel 8 .

\section{KESIMPULAN DAN SARAN}

\section{a. Kesimpulan}

Berdasarkan hasil analisis dengan penerapan algoritma Simple Additive Weighting (SAW) dapat disimpulkan sebagai berikut:

1. Kriteria yang digunakan dalam menentukan penerima beasiswa kurang mampu yaitu Penghasilan orang tua(C1), tanggungan orang tua(C2), jumlah saudara kandung(3), dan jumlah pengeluaran orang tua(4).

2. Diperoleh ranking tiga besar nilai siswa dari yang tertinggi sampai terendah yaitu A9=0.892, A10 $=0.866$, dan A5=0,826.

3. Berdasarkan informasi ranking tersebut, kepala sekolah dapat menjadikan acuran untuk memilih dan menetapkan siswasiswi yang berhak menerima beasiswa kurang mampu.

\section{b. Saran}

Adapun saran-saran dari penulis untuk sistem ini adalah sebagai berikut:

1. Bagi peneliti, dapat menjadikan artikel ini sebagai referensi dalam meneliti kasuskasus yang lain.

2. Penelitian ini dapat dikembangkan menjadi suatu aplikasi sistem pendukung keputusan.

\section{REFERENSI}

[1] Murniasih, Erny. "Buku Pintar Beasiswa". Jakarta : Gagas Media.2009.

[2] Dauni, dkk. "Implementasi metode Grabbing Pada Web Penyedia Informasi Beasiswa”, JURNAL TEKNIK. 2009.

[3] Kusumaewi, Hartati S., Harjoko A, dan Wardoyo, R. "Fuzzy Multi Attributte Decision Making (Fuzzy MADM)”,Yogyakarta: Graha Ilmu. 2006 
[4] Nofriansyah D. "Konsep Data Mining VS Sistem Pendukung Keputusan". Yogyakarta, Daerah Istimewa Yogyakarta, Indonesia: CV. Budi Utama. 2014

[5] Rinaldhi, Eka G., "Penerapan Metode Simple Additive Weighting (SAW) untuk Sistem Pendukung Keputusan Penentuan Penerimaan Beasiswa bantuan Siswa Miskin (BSM) pada SMA Negeri 1 Subah Kab. Batang”, UDN, 2013.

[6] Hasanah R,. "Sistem Pendukung Keputusan Untuk Menentukan PenerimaBeasiswa Dengan Metode Simple Additive Weighting (Saw) (Studi Kasus Pada Mts Al-Maidah Kotasan)". Jurnal Pelita InformatikaBudi Darma. Volume : V, Nomor: 3, Desember 2013 ISSN : 2301-9425

[7] Dyah, Pratiwi, Sistri,. "Sistem Pendukung Keputusan Penerimaan Dana Bantuan Siswa Miskin Menggunakan Metode Simple Additive Weigthing (study kasus SDN Kesek 2 kecamatan Labang Bangkalan)".Jurnal Management Informatika. Fakultas Teknik, Universitas Trunojoyo. 2014.

[8] Resti N. C,. "Penerapan Metode Simple Additive Weighting (SAW) pada Sistem Pendukung Keputusan Pemilihan Lokasi untuk Cabang Baru Toko Pakan UD. Indo Multi Fish", Jurnal INTENSIF, Vol.1 No.2 Agustus

ISSN: 2580-409X (Cetak) / 2549-6824 (Online)

[9] Rini A.S, Soyusiawaty D,. "Sistem Pendukung Keputusan Seleksi Penerimaan Beras Untuk Keluarga Miskin Dengan Metode Simple Additive Weighting", Jurnal Sarjana Teknik Informatika E-Issn:23385197 Volume 2 Nomor 2, Juni 2014.

[10] Fauzan R, Indrasary Y, Muthia N, (2017). "Sistem Pendukung Keputusan Penerimaan Beasiswa Bidik Misi di POLIBAN Dengan Metode SAW Berbasis Web", JOIN (Jurnal Online Informatika) Volume 2 No. 2 Desember 2017: 79-83 DOI: $10.15575 /$ join.v2i2.101 